\title{
COMMENTARY
}

\section{Defining the adequate arterial pressure target during septic shock: not a 'micro' issue but the microcirculation can help}

\author{
Serena Silva' and Jean-Louis Teboul ${ }^{* 1,2}$ \\ See related research by Thooft et al., http://ccforum.com/content/15/5/R222
}

\begin{abstract}
The Surviving Sepsis Campaign guidelines suggest targeting a mean arterial pressure of at least $65 \mathrm{~mm}$ $\mathrm{Hg}$ to maintain organ perfusion pressure during septic shock. However, the optimal mean arterial pressure can be higher in patients with a history of hypertension or other vascular comorbidities or in those with increased abdominal pressure. In a given individual, the adequate mean arterial pressure target can be difficult to define with the routine hemodynamic parameters (for example, cardiac output, central or mixed venous blood oxygen saturation, and urine output). Nearinfrared spectroscopy and sidestream dark field imaging have emerged as promising technologies for monitoring the microcirculation at the bedside. These new methods could provide additional clues to help define the adequate blood pressure to target during the resuscitation phase of septic shock.
\end{abstract}

In a study in the previous issue of Critical Care, Thooft and colleagues [1] investigated the impact of increasing mean arterial pressure (MAP) by norepinephrine (NE) on systemic hemodynamics and organ perfusion in a series of patients with septic shock. The increase in MAP from 65 to $85 \mathrm{~mm} \mathrm{Hg}$ was associated with increased cardiac output and mixed venous blood oxygen saturation $\left(\mathrm{SvO}_{2}\right)$ and a decreased blood lactate level. The increase in MAP was also associated with improvement of the microcirculation state as assessed by near-infrared

*Correspondence: jean-louis.teboul@bct.aphp.fr

'AP-HP, Hôpitaux universitaires Paris-Sud, Hôpital de Bicêtre, Service de réanimation médicale, 78, rue du Général Leclerc, Le Kremlin-Bicêtre, F-94270 France

Full list of author information is available at the end of the article spectroscopy (NIRS) at the thenar eminence level in 13 patients and by sidestream dark field (SDF) imaging at the sublingual level in 6 of them. NIRS technology allows investigators to evaluate the functionality of the thenar eminence microcirculation through the measurement of the muscle tissue oxygen saturation $\left(\mathrm{StO}_{2}\right)$ and its changes in response to a vascular occlusion test (VOT). SDF videomicroscopy allows investigators to assess the sublingual microvascular blood flow and capillary density by using several indices [2]. The presence of marked microvascular abnormalities detected by each of these techniques has been associated with increased mortality in septic shock [3,4].

Before being enrolled, the patients of Thooft and colleagues [1] had already been stabilized at an MAP of $65 \mathrm{~mm} \mathrm{Hg}$ with fluid therapy and NE administration and their $\mathrm{SvO}_{2}$ was above $65 \%$, in accordance with Surviving Sepsis Campaign guidelines [5]. Although these goals appeared to have been achieved, severe derangements of organ perfusion were detected by both the NIRS and SDF techniques. This agrees with the concept that, in septic shock, microcirculatory abnormalities can persist despite apparent correction of macrocirculatory abnormalities $[4,6,7]$. However, it is still unclear whether the persistence of microcirculatory abnormalities at the early phase is related only to intrinsic septic organ/tissue injury or is a consequence of insufficient macro-hemodynamic resuscitation and, in particular, achievement of a still suboptimal organ perfusion pressure. Current recommendations suggest an MAP of at least $65 \mathrm{~mm} \mathrm{Hg}$ given that, in patients with a history of hypertension or other vascular comorbidities or in those with increased abdominal pressure, a higher level of MAP may be required [5]. However, increasing the doses of NE carries the theoretical double risk of (a) decreasing cardiac output and oxygen delivery through an increased afterload effect and (b) worsening tissue perfusion through excessive peripheral vasoconstriction. Recent studies have evaluated the effects on cardiac output and organ 
perfusion markers of using NE to increase MAP from 60 (or 65) $\mathrm{mm} \mathrm{Hg}$ to 85 (or 90) $\mathrm{mm} \mathrm{Hg}$ in patients with septic shock [8-10]. All of the studies supported the idea that, in spite of the increase in cardiac output, achieving the upper MAP target is not always associated with a remarkable improvement in organ perfusion.

In contrast to previous studies, the study by Thooft and colleagues [1] demonstrated that an MAP target of $85 \mathrm{~mm} \mathrm{Hg}$ might be more appropriate than $65 \mathrm{~mm} \mathrm{Hg}$ for the microcirculation. One of the strengths of the study is that these results were found by using two different techniques: NIRS and SDF imaging. The higher $\mathrm{StO}_{2}$ reperfusion slope (during a VOT) at the highest level of MAP suggests that some degree of microvascular recruitment occurred at this level, confirming results found in patients with severely hypotensive sepsis [11]. In addition, increasing MAP from 65 to $85 \mathrm{~mm} \mathrm{Hg}$ significantly improved two of the SDF-derived indices: the perfused vessel density and the microvascular flow index [1]. This suggests that both microvessel recruitment and microcirculatory blood flow increased at the MAP of $85 \mathrm{~mm} \mathrm{Hg}$. These findings can be the result either of a proper perfusion pressure effect in some pressuredependent areas or of the increase in systemic blood flow observed at the highest level of MAP. The association of increases in cardiac output with NE-induced increases in MAP is a common finding that has been reported previously [8-13]. Clearly, the results of Thooft and colleagues [1] argue against the idea that, owing to excessive vasoconstriction, NE could exert deleterious effects on the microcirculation when an MAP of $85 \mathrm{~mm} \mathrm{Hg}$ is targeted. It is important to note that $85 \mathrm{~mm} \mathrm{Hg}$ is still low compared with MAP values of the healthy population [14], especially in the age group of the study by Thooft and colleagues [1].

Because the SDF analysis was conducted on only 6 of the 13 patients in the study by Thooft and colleagues [1], the interpretation of their data must be cautious. It must be underlined that, using study designs similar to that of Thooft and colleagues in the early phase of septic shock, Jhanji and colleagues [9] and Dubin and colleagues [10] reported no overall change in sublingual SDF-derived variables with NE-induced increases in MAP (above $60 \mathrm{~mm} \mathrm{Hg}$ in 16 patients and $65 \mathrm{~mm} \mathrm{Hg}$ in 20 patients, respectively). Nevertheless, Dubin and colleagues [10] reported an inverse correlation between the baseline level of the sublingual microcirculation state and the microcirculatory response to the NE-induced increase in MAP from 65 to $85 \mathrm{~mm} \mathrm{Hg}$. Thus, septic patients with normalized microcirculation (after initial hemodynamic resuscitation) might not benefit from any additional increase in MAP above $65 \mathrm{~mm} \mathrm{Hg}$. In contrast, septic patients with persistent altered microcirculation, though Surviving Sepsis Campaign recommended endpoints are achieved, might benefit from a further increase in MAP beyond the 'magic' value of $65 \mathrm{~mm} \mathrm{Hg}$. The results of Thooft and colleagues [1] are in agreement with this sensible concept, which clearly needs to be implemented in clinical practice.

This paper [1], like other recent ones [7,15,16], has the merit of bringing to light the idea that, at least during the early phase of sepsis, the microcirculation is not dissociated from the macrocirculation, despite what is claimed by pioneers of the microcirculation evaluation. More importantly, the paper suggests that bedside assessment of microcirculation might help clinicians to define the optimal level of macrocirculatory resuscitation targets (for example, MAP and $\mathrm{SvO}_{2}$ ) in each patient.

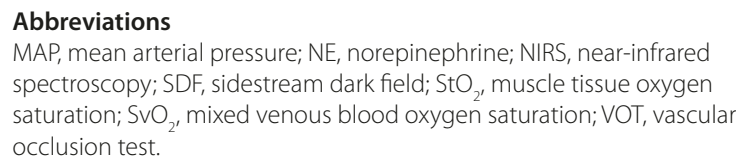

\section{Author details}

${ }^{1}$ AP-HP, Hôpitaux universitaires Paris-Sud, Hôpital de Bicêtre, Service de réanimation médicale, 78, rue du Général Leclerc, Le Kremlin-Bicêtre, F-94270 France. ${ }^{2}$ Univ Paris-Sud, Faculté de médecine Paris-Sud, EA 4046, 63, rue Gabriel Péri, Le Kremlin-Bicêtre, F-94270 France Le Kremlin-Bicêtre, F-94270 France.

\section{Published: 2 November 2011}

\section{References}

1. Thooft A, Favory R, Salgado-Ribeiro D, Taccone FS, Donadello K, De Backer D, Creteur J, Vincent JL: Effects of changes in arterial pressure on organ perfusion during septic shock. Crit Care 2011, 15:R222.

2. De Backer D, Hollenberg S, Boerma C, Goedhart P, Büchele G, Ospina-Tascon $G$, Dobbe I, Ince C: How to evaluate the microcirculation: report of a round table conference. Crit Care 2007, 11:R101.

3. Creteur J, Carollo T, Soldati G, Buchele G, De Backer D, Vincent JL: The prognostic value of muscle $\mathrm{StO} 2$ in septic patients. Intensive Care Med 2007, 33:1549-1556.

4. Sakr Y, Dubois MJ, De Backer D, Creteur J, Vincent JL: Persistent microcirculatory alterations are associated with organ failure and death in patients with septic shock. Crit Care Med 2004, 32:1825-1831.

5. Dellinger RP, Levy MM, Carlet JM, Bion J, Parker MM, Jaeschke R, Reinhart K, Angus DC, Brun-Buisson C, Beale R, Calandra T, Dhainaut JF, Gerlach H, Harvey M, Marini J, Marshall J, Ranieri M, Ramsay G, Sevransky J, Thompson BT, Townsend S, Vender JS, Zimmerman JL, Vincent JL: Surviving Sepsis Campaign: international guidelines for management of severe sepsis and septic shock: 2008. Crit Care Med 2008, 36:296-332.

6. De Backer D, Creteur J, Preiser JC, Dubois MJ, Vincent JL: Microvascular blood flow is altered in patients with sepsis. Am J Respir Crit Care Med 2002, 166:98-104.

7. Trzeciak S, Dellinger RP, Parrillo JE, Guglielmi M, Bajaj J, Abate NL, Arnold RC, Collila Z, Zanotti S, Hollenberg SM: Microcirculatory Alterations in Resuscitation and Shock (MARS) Investigators (2007) Early Microcirculatory perfusion derangements in patients with severe sepsis and septic shock: relationship to hemodynamics, oxygen transport, and survival. Ann Emerg Med 2007, 49:88-98.

8. LeDoux D, Astiz ME, Carpati CM, Rackow EC: Effects of perfusion pressure on tissue perfusion in septic shock. Crit Care Med 2000, 28:2729-2732.

9. Jhanji S, Stirling S, Patel N, Hinds CJ, Pearse RM: The effect of increasing doses of norepinephrine on tissue oxygenation and microvascular flow in patients with septic shock. Crit Care Med 2009, 37:1961-1966.

10. Dubin A, Pozo MO, Casabella CA, Pálizas F Jr., Murias G, Moseinco MC, 
Kanoore Edul VS, Pálizas F, Estenssoro E, Ince C: Increasing arterial blood pressure with norepinephrine does not improve microcirculatory blood flow: a prospective study. Crit Care 2009, 13:R92.

11. Georger JF, Hamzaoui O, Chaari A, Maizel J, Richard C, Teboul JL: Restoring arterial pressure with norepinephrine improves muscle tissue oxygenation assessed by near-infrared spectroscopy in severely hypotensive septic patients. Intensive Care Med 2010, 36:1882-1889.

12. Deruddre S, Cheisson G, Mazoit JX, Vicaut E, Benhamou D, Duranteau J: Renal arterial resistance in septic shock: effects of increasing mean arterial pressure with norepinephrine on the renal resistive index assessed with Doppler ultrasonography. Intensive Care Med 2007, 33:1557-1562.

13. Hamzaoui O, Georger JF, Monnet X, Ksouri H, Maizel J, Richard C, Teboul JL: Early administration of norepinephrine increases cardiac preload and cardiac output in septic patients with life-threatening hypotension. Crit Care 2010, 14:R142.

14. McVeigh GE, Bratteli CW, Morgan DJ, Alinder CM, Glasser SP, Finkelstein SM, Cohn JN: Age related abnormalities in arterial compliance identified by pressure pulse contour analysis: aging and arterial compliance. Hypertension 1999, 33:1392-1398.

15. Pottecher J, Deruddre S, Teboul JL, Georger JF, Laplace C, Benhamou D, Vicaut $\mathrm{E}$, Duranteau J: Both passive leg raising and intravascular volume expansion improve sublingual microcirculatory perfusion in severe sepsis and septic shock patients. Intensive Care Med 2010, 36:1867-1874.

16. Ospina-Tascon G, Neves AP, Occhipinti G, Donadello K, Büchele G, Simion D, Chierego ML, Silva TO, Fonseca A, Vincent JL, De Backer D: Effects of fluids on microvascular perfusion in patients with severe sepsis. Intensive Care Med 2010, 36:949-955.

doi:10.1186/cc10486

Cite this article as: Silva S, Teboul J-L: Defining the adequate arterial pressure target during septic shock: not a 'micro' issue but the microcirculation can help. Critical Care 2011, 15:1004. 